\title{
Effect of Removing the Glipped Kidney on Renovascular Hypertension in Rabbits
}

\author{
Jun Fujir, M.D., Yoshio Yazaki, M.D., \\ Akira Seki, M.D., and Morio Kuramochi, M.D.
}

\begin{abstract}
SUMMARY
Constriction of one renal artery in the presence of the opposite kidney can produce persistent hypertension which is often associated with increase in plasma renin activity, decrease in serum potassium and increase in water intake. In the present study the clipped kidney was removed in 15 hypertensive rabbits 12 to 54 weeks after the constriction. Blood pressure showed a prompt and transient fall which was followed by a slight rebound and subsequently a gradual decline. However, it still remained above the normal 5 weeks after the removal. Removal of the clipped kindney resulted in return to normal of increased plasma renin activity, decreased serum potassium and increased water intake at the end of the postoperative first week.
\end{abstract}

\section{Additional Indexing Words :}

Renin Serum potassium Water intake

CONSTRICTION of one renal artery can produce persistent hypertension 1 in rats, ${ }^{1,2)}$ rabbits, ${ }^{3,4}$, and $\operatorname{dog} s^{51}$ even if the opposite kidney is left intact. The effect of removing the clipped kidney on hypertension of this type has been studied in rats, ${ }^{11,61,7)}$ rabbits, ${ }^{4)}$ and dogs. ${ }^{5}$ ) Removal of the clipped kidney is generally followed by a fall in blood pressure, but whether or not the blood pressure can return to normal remains a subject of controversy.

The hypertension produced by clipping one renal artery in the presence of an intact contralateral kidney is often associated with increase in plasma renin activity, decrease in serum potassium and increase in water intake. ${ }^{81-10}$ However, there is little information about the effect of removing the clipped kidney on these metabolic derangements. The present study was attempted to observe the effect of removing the clipped kidney not only on blood pressure but also on plasma renin activity, serum potassium and water intake in hypertensive rabbits. A part of the present study was previously reported in a preliminary form. ${ }^{111}$ Tokyo.

From the Institute for Adult Diseases, Asahi Life Foundation, 1-9-14 Nishishinjuku, Shinjuku,

Received for publication May 8, 1974. 


\section{METHOD}

The present study was carried out on 15 hypertensive rabbits. Male rabbits weighing 2.0 to $2.5 \mathrm{Kg}$ were fed standard pellets for the rabbit (CR 1, Japan Clea Ltd) which contain $14 \mathrm{mEq}$ of sodium and $28 \mathrm{mEq}$ of potassium per $100 \mathrm{Gm}$. Each animal was given $100 \mathrm{Gm}$ of the pellets and water ad libitum. Hypertension was produced by applying a silver clip of $0.9 \mathrm{~mm}$ id on the left renal artery. The right kidney was left intact. After establishment of persistent hypertension the clipped kidney was removed. Persistent hypertension was defined in the present study as blood pressure that had been elevated above $120 \mathrm{mmHg}$ over the past 5 weeks or more. The interval between clipping of the renal artery and removal of the clipped kidney ranged from 12 to 54 weeks. Operative procedures were performed through a small flank incision under sodium pentobarbital anesthesia $(30 \mathrm{mg} / \mathrm{Kg}$, iv). Blood pressure was measured by an indirect method ${ }^{12)}$ on the central ear artery of unanesthetized animals usually at a weekly interval.

Plasma renin activity (PRA), serum sodium and serum potassium were measured just before, 1 and 4 weeks after removing the clipped kidney. About $10 \mathrm{ml}$ of blood were taken by a heparinized syringe from the ear vein of resting animals without anesthesia for the measurement of PRA, and thereafter about $3 \mathrm{ml}$ of blood by a dry syringe for the measurement of serum electrolytes. PRA was determined by the method of Pickens et $\mathrm{al}^{13)}$ with a minor modification. ${ }^{4)}$ Values for renin

Table I. Blood Pressure, Serum Potassium, Water Intake, and Plasma Renin Activity before and after Removal of the Clipped Kidncy

\begin{tabular}{|c|c|c|c|c|c|c|c|c|c|c|c|c|c|}
\hline \multirow{3}{*}{$\begin{array}{c}\text { No. } \\
1\end{array}$} & \multirow{3}{*}{$\begin{array}{c}\begin{array}{c}\text { Interval } \\
\text { after } \\
\text { Clipping } \\
\text { (Weeks) }\end{array} \\
40\end{array}$} & \multirow{2}{*}{\multicolumn{3}{|c|}{\begin{tabular}{l} 
B. P. (mmHg) \\
\hdashline $0 \begin{array}{c}1 \\
\text { (Weeks) }\end{array} 4$
\end{tabular}}} & \multicolumn{3}{|c|}{ Serum K (mEq/L) } & \multicolumn{3}{|c|}{$\begin{array}{l}\text { Water Intake } \\
\text { (ml/day) }\end{array}$} & \multicolumn{3}{|c|}{ PRA (ng/ml) } \\
\hline & & & & & 0 & 1 & $\begin{array}{l}4 \\
\text { s) }\end{array}$ & \multicolumn{3}{|c|}{$0 \begin{array}{c}1 \\
\text { (Weeks) }\end{array}$} & \multicolumn{3}{|c|}{$c^{1}{ }_{\text {(Weeks) }}^{4}$} \\
\hline & & 184 & 143 & 117 & 4.0 & 3.5 & 3.5 & 413 & 302 & 300 & 1.6 & 1.2 & 3.2 \\
\hline 2 & 26 & 130 & 100 & 97 & 2.7 & 3.3 & 3.7 & 706 & 378 & 337 & 25.9 & 0.9 & 0.4 \\
\hline 3 & 22 & 143 & 137 & 98 & 3.6 & 4.5 & 3.4 & 306 & 272 & 298 & 2.5 & 1.0 & 3.8 \\
\hline 4 & 48 & 141 & 128 & 120 & 3.7 & 4.1 & 3.9 & 737 & 442 & 546 & 1.6 & 2.0 & 1.6 \\
\hline 5 & 51 & 170 & 143 & 105 & 4.1 & 4.8 & 4.1 & 729 & 607 & 664 & 1.5 & 1.6 & 3.2 \\
\hline 6 & 43 & 174 & 144 & 122 & 2.9 & 3.5 & 4.0 & 836 & 719 & 669 & 6.1 & 0.8 & 4.0 \\
\hline 7 & 12 & 171 & 152 & 141 & 3.0 & 4.6 & 4.0 & 659 & 506 & 396 & 1.8 & 0.4 & 1.2 \\
\hline 8 & 17 & 169 & 160 & 130 & 2.3 & 3.2 & 4.1 & 782 & 514 & 569 & 21.6 & 0.5 & 2.2 \\
\hline 9 & 17 & 155 & 98 & 83 & 2.3 & 2.9 & 4.2 & 846 & 615 & 659 & 41.2 & 0.2 & 0.5 \\
\hline 10 & 42 & 171 & 115 & 129 & 3.5 & 4.0 & 3.8 & 407 & 317 & 236 & 52.6 & 0.8 & 6.3 \\
\hline 11 & 54 & 151 & 136 & 112 & 3.3 & 3.4 & 3.5 & 603 & 416 & 340 & 14.0 & 2.4 & 5.0 \\
\hline 12 & 25 & 183 & 160 & 138 & 2.8 & 3.5 & 3.9 & 691 & 493 & 330 & 28.2 & 2.2 & 4.4 \\
\hline 13 & 50 & 157 & 142 & 122 & 3.5 & 4.0 & 3.5 & 617 & 355 & 334 & 16.6 & 1.6 & 1.0 \\
\hline 14 & 52 & 160 & 103 & 110 & 3.2 & 4.0 & 4.0 & 353 & 323 & 304 & 1.6 & 1.8 & 1.2 \\
\hline \multirow[t]{3}{*}{15} & 18 & 174 & 135 & 99 & 2.1 & 4.1 & 4.6 & 651 & 363 & 350 & 20.0 & 2.6 & 8.2 \\
\hline & Means & 162 & 133 & 115 & 3.13 & 3.87 & 3.88 & 622 & 441 & 422 & 15.8 & 1.3 & 2.9 \\
\hline & SE & 4 & 5 & 4 & 0.14 & 0.15 & 0.08 & 45 & 34 & 40 & 4.1 & 0.2 & 0.6 \\
\hline
\end{tabular}


activity were expressed as nanograms (ng) angiotensin II amide (Hypertensin, Ciba) equivalents generated per $\mathrm{ml}$ of plasma after incubation of 4 hours. Serum sodium and potassium were determined by flame photometry. Water intake was measured every day by weighing the water bottles in the period from 2 weeks before to 3 weeks after removal of the clipped kidney. Values for the water intake were expressed as an average of values for the past 7 days.

Average values obtained from 20 normal animals were $85.5 \pm 6.7$ (SD) $\mathrm{mmHg}$ ranging from $76 \mathrm{mmHg}$ to $104 \mathrm{mmHg}$ for blood pressure, $3.1 \pm 2.0 \mathrm{ng} / \mathrm{ml}$ ranging from $1.0 \mathrm{ng} / \mathrm{ml}$ to $9.7 \mathrm{ng} / \mathrm{ml}$ for PRA, $140.9 \pm 2.2 \mathrm{mEq} / \mathrm{L}$ ranging from $136 \mathrm{mEq} / \mathrm{L}$ to $146 \mathrm{mEq} / \mathrm{L}$ for serum sodium, and $3.90 \pm 0.26 \mathrm{mEq} / \mathrm{L}$ ranging from $3.4 \mathrm{mEq} / \mathrm{L}$ to $4.5 \mathrm{mEq} / \mathrm{L}$ for serum potassium. An average for water intake obtained from 18 normal animals was $436 \pm 120 \mathrm{ml} /$ day ranging from $271 \mathrm{ml} /$ day to $659 \mathrm{ml} /$ day.

\section{Results}

The data on individual animals are presented in Table $I$ and the changes in average values are illustrated in Figs. 1 and 2. Changes in PRA are individually illustrated in Fig. 3.

Blood pressure was measured every day during the first 7 days. As shown in Fig. 1, removal of the clipped kidney induced an abrupt and transient fall in blood pressure which was followed by a slight rebound. In the subsequent

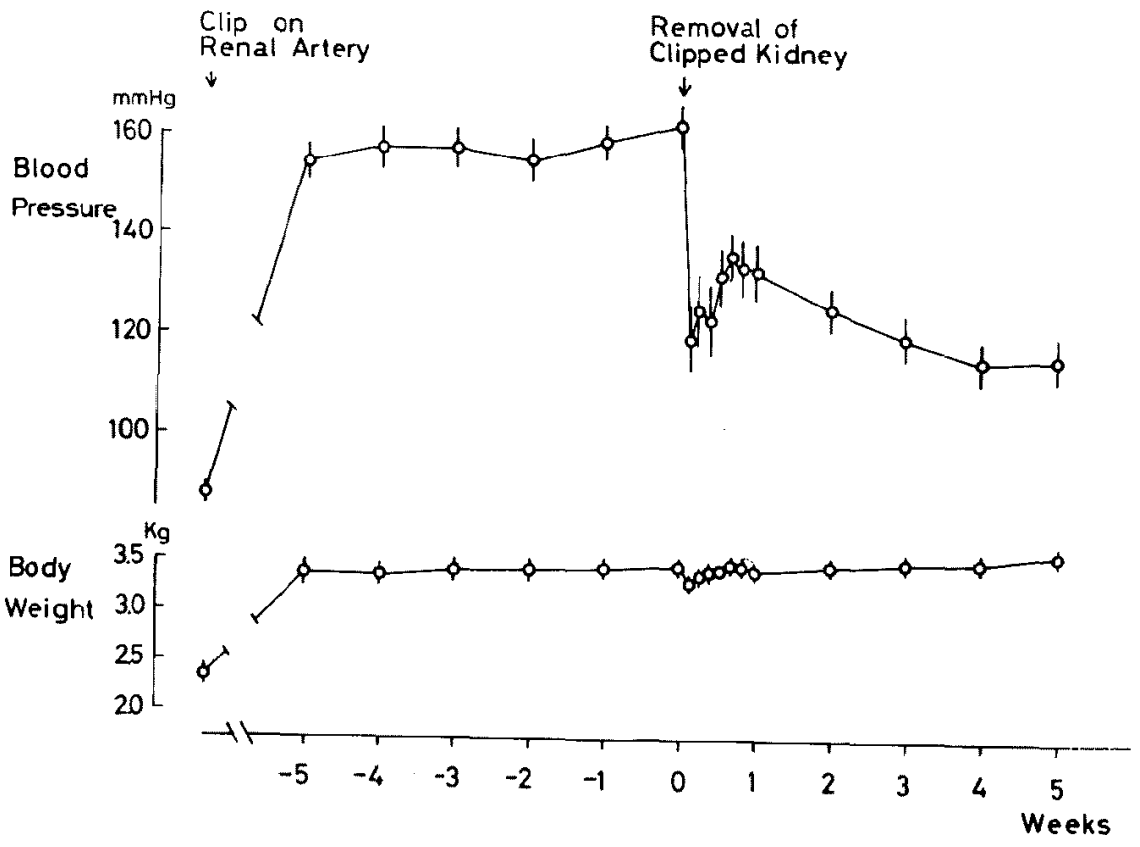

Fig. 1. Effect of removing the clipped kidney on blood pressure and body weight. Values are means $\pm \mathrm{SE}(\mathrm{N}=15)$. 

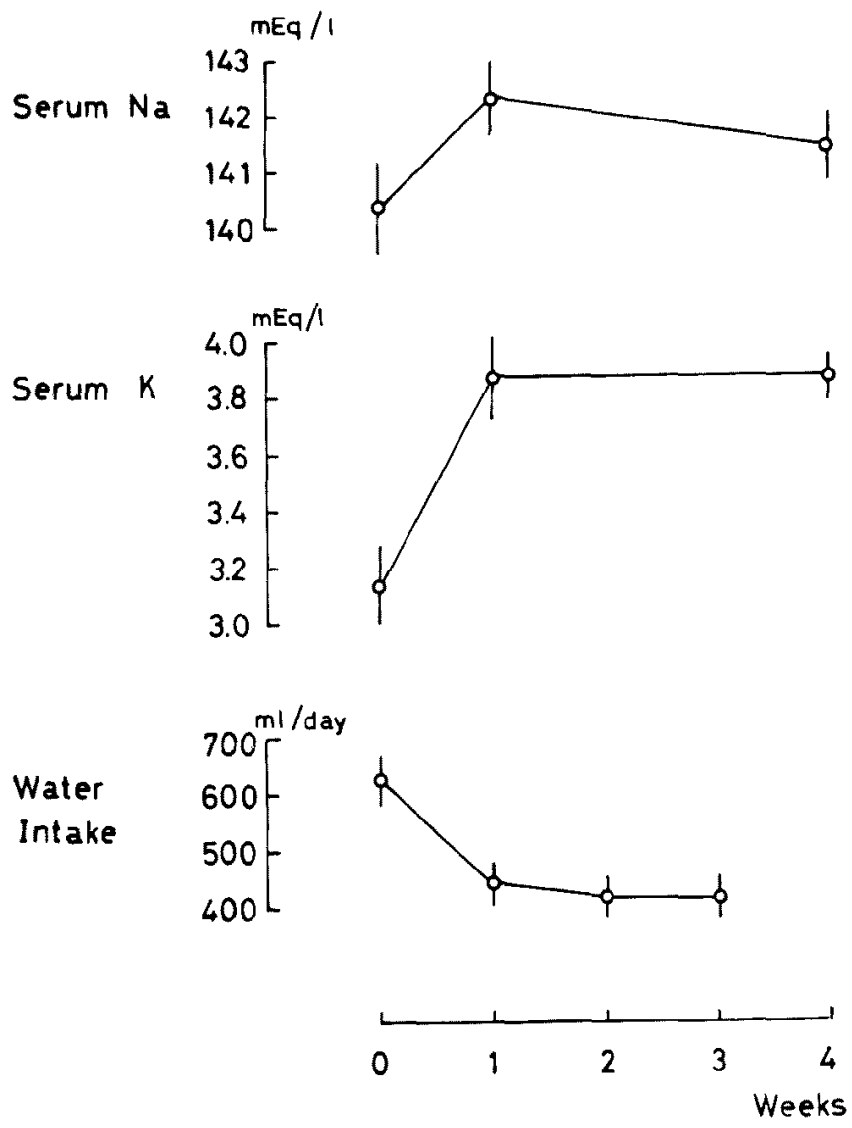

Fig. 2. Changes in serum sodium $(\mathrm{Na})$, serum potassium $(\mathrm{K})$ and water intake before and after removing the clipped kidney. Values are means $\pm \mathrm{SE}(\mathrm{N}=15)$. Removal of the clipped kidncy at time zero.

course to the 5th week blood pressure gradually fell to a lower level which still remained higher than normal. Any significant relationship did not exist between the fall in blood pressure and the interval from clipping of the renal artery to removal of the clipped kidney. For example, animal No. 7 was operated upon for removing the clipped kidney 12 weeks after clipping. The interval from clipping to removing was the shortest among the animals, but blood pressure only slightly fell from $171 \mathrm{mmHg}$ to $141 \mathrm{mmHg}$ after 4 weeks. Animal No. 14 showed a prompt and marked fall in blood pressure from 160 $\mathrm{mmHg}$ to $103 \mathrm{mmHg}$ at the end of the first week although the clipped kidney was removed as long as 52 weeks after clipping.

As shown in Table $I$, serum potassium was below the normal range in 9 of 15 hypertensive animals. Removal of the clipped kidney was followed by return to normal of serum potassium at the end of the first week in 8 of the 9 


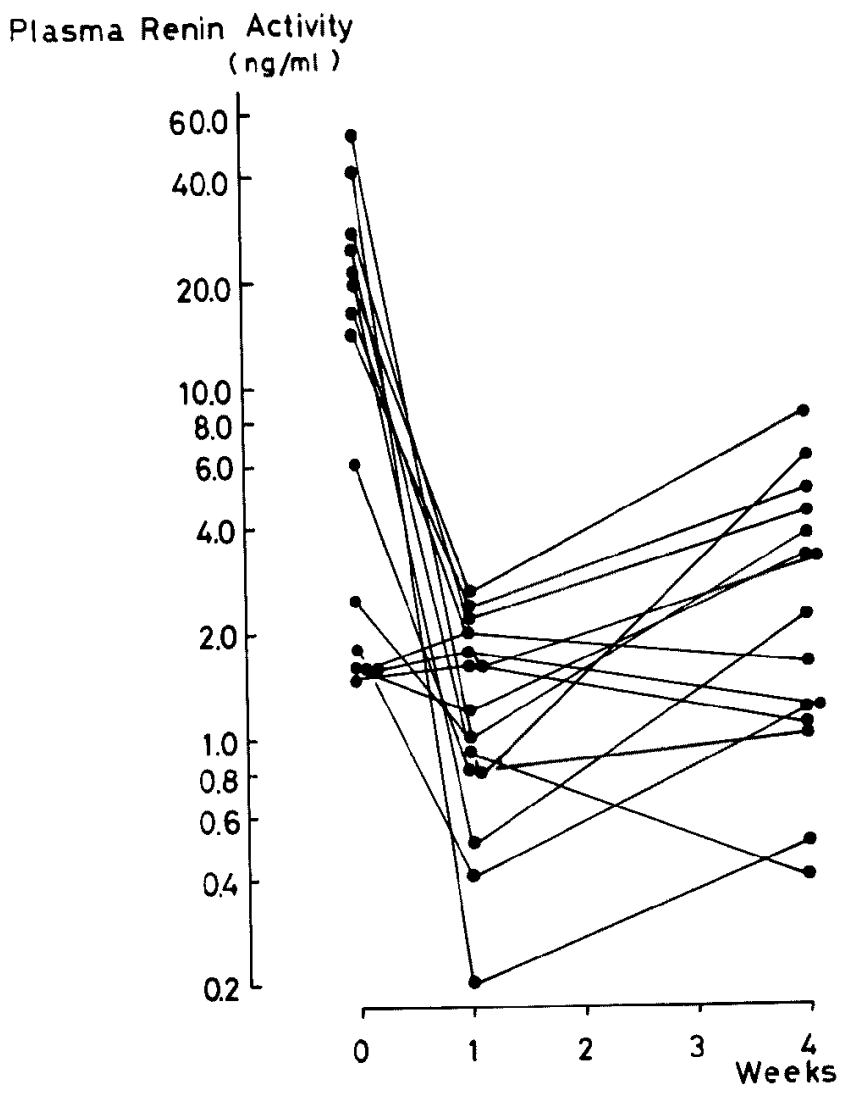

Fig. 3. Changes in plasma renin activity of individual animals before and after removing the clipped kidney. Values of plasma renin activity are plotted on a logarithmic scale. Removal of the clipped kidney at time zero.

animals. After removing the clipped kidney serum potassium was also increased in 5 of 6 animals that had showed normal serum potassium values. An average of serum potassium in all 15 animals was $3.13 \pm 0.14(\mathrm{SE}) \mathrm{mEq} / \mathrm{L}$ before, $3.87 \pm 0.15 \mathrm{mEq} / \mathrm{L} \mathrm{l}$ week and $3.88 \pm 0.08 \mathrm{mEq} / \mathrm{L} 4$ weeks after removing. The increments of serum potassium were highly significant $(p<$ 0.001 , respectively). Serum sodium was within normal range in 14 of 15 hypertensive animals. After removal of the clipped kidney an average of serum sodium showed a transient and slight increase from $140.4 \pm 0.8 \mathrm{mEq} / \mathrm{L}$ to $142.4 \pm 0.6 \mathrm{mEq} / \mathrm{L}$ at the end of the first week. The increment was statistically significant $(\mathrm{p}<0.05)$.

Water intake was increased above the normal range in 7 of 15 hypertensive animals. After removal of the clipped kidney it returned to normal in 6 of the 7 animals at the end of the first week. An average of water intake in all 
15 animals was decreased from $622 \pm 45 \mathrm{ml} /$ day to $441 \pm 34 \mathrm{ml} /$ day after 1 week and to $442 \pm 40 \mathrm{ml} /$ day after 3 weeks. The decrements of water intake was significant both at the end of the first and at the end of the third week ( $\mathrm{p}<0.01$, respectively).

PRA was elevated above the normal range in 8 of 15 hypertensive animals. Removal of the clipped kidney resulted in a prompt fall in PRA to normal or subnormal level at the end of the first week in all of the 8 animals (Fig. 3). At the end of the 4th week PRA showed a slight rebound in most animals. There was not sufficient evidence to indicate any relationship between preoperative values of PRA and responses of blood pressure to removing the clipped kidney. Considerable fall in blood pressure was observed also in animals with normal values of PRA.

\section{Discussion}

Previous studies from our laboratory ${ }^{3 / 4}$ ) have revealed that in the presence of the opposite kidney constriction of one renal artery can produce persistent hypertension in rabbits. The hypertension sharply differs from hypertension produced by clipping of one renal artery with contralateral nephrectomy. ${ }^{8), 10)}$ Metabolic derangements including increase in PRA, decrease in serum potassium and increase in water intake were observed only in the former type of hypertension. The difference in PRA and sodium metabolism between the 2 types of hypertension was observed in rats by Gross ${ }^{14)}$ and Swales et al.15),16) The present study demonstrated that removal of the clipped kidney was followed by a fall in blood pressure and return to normal of the metabolic derangements. The results suggest that the presence of both clipped and intact kidney is essential to the development of the metabolic derangements. In the present study a slight but significant increase in serum sodium was transiently observed at the end of the first week. However, the changes in serum sodium were really slight in comparison with those in serum potassium.

Lupu et $\mathrm{al}^{5)}$ reported that removal of the clipped kidney uniformly resulted in return of bood pressure to normal in dogs even as long as 16 months after clipping of the renal artery. The present study showed that removal of the clipped kidney could reduce blood pressure but not to the normal level. Kolestky and Rivera-Velez ${ }^{7)}$ demonstrated that the fall in blood pressure by removing the clipped kidney was closely related to the duration of hypertension in rats. Removal of the clipped kidney resulted in a complete return of blood pressure to normal in animals which were hypertensive for 3 days or 1 week. The fall in blood pressure was smaller and less prompt with hypertension of 2 or 3 weeks' duration and often slight or insignificant at 4 wceks. The present 
study did not reveal any relationship between the duration of hypertension and the responses of blood pressure to removing the clipped kidney.

In the present study an abrupt and transient fall in blood pressure was observed during a few days just after removal of the clipped kidney. This observation suggests that 2 different mechanisms are involved in maintenance of hypertension. One may rapidly and the other may slowly disappear after removal of the clipped kidney. The abrupt and transient fall in blood pressure may be attributed to a rapid loss of one hypertensive mechanism and the gradual fall in blood pressure during the several weeks may be attributed to a slow loss of the other hypertensive mechanism.

The present study showed that the fall in blood pressure was not necessarily parallel to that in PRA. At the end of the first week blood pressure still remained high in some animals in spite of return to normal of PRA and metabolic derangements.

\section{AcKNowledgements}

The authors gratefully acknowledge the technical assistance of Mr. S. Ushiama, Mr. H. Irie, and Miss S. Koriyama.

This study was supported, in part, by a grant from the Takeda Science Foundation.

Y. Yazaki, A. Seki and M. Kuramochi are visiting scientists from the Third Department of Internal Medicine, Faculty of Medicine, University of Tokyo.

\section{REFERENGES}

1. Wilson C, Byrom FB: Renal changes in malignant hypertension. Lancet 1: 136, 1939

2. Byrom FB, Dodson LF: The mechanism of the vicious circle in chronic hypertension. Clin Sci 8: 1, 1949

3. Fujii J, Kurihara H, Yamaguchi H, Terasawa F, Murata K, Matsushita S, Ikeda M: A persistent hypertension due to unilateral renal-artery constriction in the rabbit. Jap Circulat J $31: 1197,1967$

4. Fujii J, Kurihara $\mathrm{H}$, Yamaguchi $\mathbf{H}$, Ikeda $\mathrm{M}$ : Salt-rich diet and experimental renovascular hypertension in the rabbit. Tohoku J exp Med 97: 191, 1969

5. Lupu AN, Maxwell MH, Kaufman JJ, White FN: Experimental unilateral renal artery constriction in the dog. Circulat Res 30; 567, 1972

6. Floyer MA: The effect of nephrectomy and adrenalectomy upon the blood pressure in hypertensive and normotensive rats. Clin Sci 10: 405, 1951

7. Koletsky S, Rivera-Velez JM: Factors determining the success or failure of nephrectomy in experimental renal hypertension. J Lab Glin Med 76: 54, 1970

8. Fujii J, Yazaki Y: Rcnin, electrolyte, and water intake in two types of experimental renal hypertension. Am J Physiol 222: 979, 1972

9. Fujii J, Yazaki Y, Kuramochi M, Seki A: High plasma renin activity and hypokalemia in rabbits with chronic renovascular hypertension. Jap Heart J 13: 340, 1972

10. Fujii J, Seki A, Kuramochi M: Contrastive profiles in two types of renovascular hypertension in rabbits. Jap Heart $\mathrm{J}$ 14: 445, 1973 
11. Fujii J, Ikeda M: Role of the renin-angiotensin system in pathogenesis of experimental renal hypertension. Jap Circulat J 35: 493, 1971

12. Kawaguchi $\mathbf{H}$ : Uber die konservative Blutdruckmessung am Kaninchen. J Chiba Med Soc 9: 293, 1931

13. Pickens PT, Bumpus FM, Lloyd AM, Smeby RR, Page IH: Measurement of renin activity in human plasma. Circulat Res 17: 438, 1965

14. Gross F: The renin angiotensin system and hypertension. Ann Intern Med 75: 777, 1971

15. Swales JD, Tange JD: The influence of acute sodium depletion on experimental hypertension in the rat. J Lab Clin Med 78: 369, 1971

16. Swales JD, Thurston $\mathrm{H}$, Queiroz FP, Medina A: Sodium balance during the development of experimental hypertension. J Lab Clin Med 80: 539, 1972 